\title{
MOTOR LEARNING METHODOLOGICAL DECISIONS ANALYSIS AND REFLEXION ON SPORTS TEACHING METHDOLOGY
}

Gerhard Hecker*

\begin{abstract}
- The author studies reading matters published over the past 25 years concerning beaviour and methodological action in a physical education class followed by

guidance and decisions for physical education teachers' performance in a Movement Learning Programme.

UNITERMS: Motor learning. Laboratory instrumental.

\section{INTRODUCTION}

Over the past 25 years three publications on the mentioned subject called special attention and greatly influenced the moulding of physical education teachers.

- Firedrich Fetz: Physical Exercise General Methodology Vienna - 1961

- Guenter Stiehler, as head of a group of authors: Methodology of Physical Education Classes

- Karl Koch and Wilhelm Mielke: The Formation of Teachining Physical Education Another four complementary volumes on this subject were published later.

Fetz begins his first chapter paraphrasing Pestalozzi: "I say that sheer
\end{abstract}

\section{* Translator's Observation (German-Portuguese)}

Due to conflicting and still non defined opinions regarding the terminology of physical education, sport and "corporal education" an explanation should be given. Accompanying the physical education process, as far as Germany is concerned, we are today faced with a situation in which the widest term is" Sport" comprising all relative areas. Thus, as this text is based on German patterns when reading the term "sport" one must be aware of its scope and not eventually associate it solely to competitive sport, for example. Within this contest one can better understand the meaning of "Sports for all" applied to areas that are technical, adapted, recreational, competitive, and so on, all implied in the term Sport. 
formation, separated, indifferent to the development of physical and moral forces of human beings, is simply a mistake" Here one could add to Pestalozzi's words, that Nature gives us the child as an inseparable whole.

Steihler believes that in school there is no need for any dualism in physical or mental education, or of moral education in a formal way. He goes on: $(1973,21)-$ "Political, ideological, moral, mental, physical, politechnical and esthetical education is not accomplished through a class subject but rather through the global process of formation and social education."

This is obvious from the teaching theory viewpoint. Nonetheless, such points do not always determine class activity of specialized teachers and besides, they are not ample enough as far as specialized methodology content is concerned. Koch and Mielke $(1968,10)$ report: However, in the area of sports, games and gymnastics activities, where the basic reasons of our standard way of movimentation are shown out of the context of a motivating and practical activity (Bernett), new sources of experience and knowledge are disclosed and with them objective possibilities which are essential to the young, in their self understanding and knowledge of the world. And later, refering to the student: what psychological and anthropological conditions given arouse a tendency towards a subject or spontaneity? In what way is a student while active motivated by what he is offered? (H. Roth) as the intensity of the effort to reach a behaviour goal will not be strong enough until the student's individuality, his psychic, physical and sensor-motor maturity besides his individual situation (Pestalozzi) are included in methodological reflexions. Thus, alongside of accuracy there is adequacy in relation to the subjective as the dominant structural moment of teaching in physical education. Therefore, it is noticed that the four authors do not regard motor learning separately. Important links with the social and psychic area are often mentioned, and Steihler shows viewpoints involving subjects and specialization.

We do not intend to call in question if readers of the mentioned literature have incorporated these general specifications and have included them in their class routine, or if they have often believed it to be pointless concentrating on a specific motor procedure in their daily classes. It is not our aim either to find out whether the four authors have faithfully followed their own claims. Particularly when it comes to the curriculum discussion and resulting stimulation for excellency, accuracy of teaching goals sets what happens in class in many more selected goal oriented schools. One of these selected goals could determine for instance that children must be able to perform the throwing skill. However, the idea of such a goal can only be sound once it is associated with a compulsion factor as operationalized formulation of learning goals. Nevertheless, many authors have pointed out that this implicit compulsion leads to a loss of important goal perspectives.

For methodological reflexions and in order to draw methodological measures from them the perspective is highly significant. Conversely, methodological reflexions and decisions can also have adverse effects on goal formulation. Over the past few years several features of this relation have been pointed out. At the same time, no reference to the interdependence or implication of this relation has been made.

At the introduction, two points must be observed:

1. Both in content and methodological decisions one must always have in mind that "nature presents us a child as an unseparable whole" For this reason, exclusive concentration on one individual aspect can not be accepted.

2. Goal, content and methodological decisions are related to one another and this relation is characterized by an implication. Thus, the following idea is put forward: methodological reflexions and decisions imply a commitment to earnestness for the identification of the existing interlinks.

\section{IS METHODOLOGY AN UNDERESTIMATED THEME IN SPORT PEDAGOGY?}

So as there be no misunderstanding, some observations concerning terminology 
are necessary. Methodology is understood as part of teaching and teaching as part of pedagogy. At the same time, teaching is used for teaching and learning processes, and methodology deals with the matter as to how goals can be reached and why given procedures are used. As competitive goals may arise in teaching and learning processes, in many cases the methods chosen cause the emphatization of a given goal. Teaching and learning concepts are more important than the concept of class, for thus a wider field is approached and above all learning situations are included for which the teacher is held responsible, but in which he may also remain secondary. In a book recently published "Determining the current situation of sport pedagogy "written by Peper and Christmann in honour of the sport pedagogue J.N. Schmitz, BrodTmann argued that class procedures are an underestimated theme in sport pedagogy. When reading the article, one realizes that the author's opinion is shwon in a very specific way. Without further appeal he explains: what the relation among goals, contents and procedures is about and that this is not always taken into account. The main point of the matter is whether methodological decisions are intended to systematize or to overcome systematization. Brodtmann clearly states that class procedures are so important that by their means, existing systems can be overcome. However such a decision can only make sense if when making the decision of goals it is made clear from the start that the system should be questloned and overcome. If this is not the goal (overcoming the system), methodological decision will be different.

All of those who are in favour of traditional sports events practised according to international rules and values, will certainly find methodological decisions different from those who achieve modifications in the sports events and who also follow an opening to the possibility of game and movement without competition guidance. Goal decisions as well as methodological ones are therefore permanently related and influencing each other, in their logical relation they are disposed in such a way that the former may perform as an explanation but never will the latter account for the decision of goals.

The mentioned priority of teaching is valid both previously and afterwards for the relation between goals and procedures.

However it is also valid for the relation between goals and contents. This does not mean that goal decisions are more important or more significant than methodological decisions. Methodological reflexions can lead to new goal ideas, however goal decisions must be accepted as distinct. It is true that we can come to the conclusion that given goals can only be reached through given procedures and that this is an indispensable link between the two decisions. Nevertheless, such statement fails to fully satisfy goal decision. A second concern is noticed in Brodtmann and it refers to the conclusion that in many cases methodological decisions are not fairly applied to the student. This surely occurs when through the method extremely fixed learning procedures are indicated and thus the students individuality is not given the necessary attention; this can not possibly be denied. By the way, as far as this theme is concerned, every teacher faces a difficult task. This is particularly true when a teacher has many students to tutor. Here the major convenience is that of the high level coach, responsible for just a few athletes.

Conversely, the teacher in a school, the sports manager in the club and the physiotherapeut in rehabilitation are under the demand for individualization.

By means of learning programmes, the problem can be worked out. Learning programmes show individual differences as regards learning period, however, in linear programmes one is concerned about every student who is given the same learning procedure. The problem was detected and efforts were made so as to carry out sub-divided programmes, in which different learning forms were possible. Nontheless for the Sports learning area the results achieved are still not satisfactory in most cases. Undoubtedly the general field of Sports Learning cannot be left to learning programmes either. Specifically under the individualization aspect the teacher can actually both adapt himself and harmonize with the student. 


\section{GUIDELINES RELATED TO THE SUBJECT MATTER}

As for the debated subject a general view of the literature cannot be offered. The aim of this text is to point out a few trends. Concerning the previously mentioned question "is methodology an underestimated theme in literature" it can be said that as for quantity the answer is no. There is a variety of publications displaying all methodological implications. Teaching plans provided by Departments or specialized associations carry detailed indications of methodological procedures to be observed in the respective learning processes. Methodological guidance is constantly offered by many specialized magazines to physical education teachers; besides there are also several theories that can be analyzed. Thus, cybernetics has "sponsored" a teaching pattern which puts forward methodological matters. All in all, information theory and the matter concerning information and how it is performed by the students are an important basis for methodological decisions. Socialization theories allow indications, which are precisely important in the social processes of learning.

The game-issue has been particularly influenced by socialization theories. (Dietrich/Landau 1976, 1977 a.b.). In this interlink, group dynamics must also be mentioned once it has provided important basic knowledge specially related to the follow up of leisure groups. It is worth mentioning here Sherif's well known experiments. The small group research concept was particularly presented in relation to Physical Education. The motivation theory has brought with it significant influence on the discussion of the methodology. This occurs because learning processes are greatly influenced by running parallel motivation rules. Here, the most important results refer to recommendations for differentiation, consideration of longer and more independent work out period for students and the relation between intrinsic and extrinsic motivation. (Hecker, 1982)

Psychology has not just given suggestions and stimuli related to theoretical learning tasks for learning procedures in sports. Methodological questions are always found whether related both to autogenous learning training and the biofeedback possibility, which may find important consideration in the learning process, or Gestalt psychology oriented tasks, which have already been related several times to learning processes in sports. (Sonnenchein, 1985, Kohl, 1956, 1977; Tholey, 1980; Gallwey, 1982; Nitsch and all, 1979; Tschakert and all, 1981).

Of course sports medicine and biomechanics can have an important role in the methodological decisions.

.(Comparatively with Wielmann's study in this volume).

The dilemma we are faced with is not lack but rather an enormous range of possible backing for methodological decisions. The new book by Rieder and Fischer "Methodology and Teaching in Sports" is particularly significant for this situation concerning leisure, school physical education, sports demanding effort, special groups where a great deal of suggestions is reported although they regret it having been impossible for them to consider all that is offered. Thus, a rich literary index and a great variety of helpful and stimulating references and indications can be found in the book. However, the book's systematic structure will surely not be fully accepted everywhere. Therefore we find ourselves faced with the task of having to summarize it in a sensible way if we are to give the teacher feasible suggestions. Surely today the articles by the four mentioned authors (Fetz, Stiehler and Koch/Mielke) are initially helpful as long as teachers manage to deal with them in a critical way. With this, special attention is drawn to the physical education teacher's ability, which in Brodtmann's article is considered ceptic however in the end it appears as the ultimate position for sound methodological decisions in individual cases.

No special effort is needed for the accomplishment of new exercises or game series; as for the teacher/student relationship much has been said; class planning and class load schedule have already been delt upon by many authors; there are many guidelines concerning teacher's speech as well as his posture before a student. All that has already been said is however always mentioned in a 
vague and non coordinated or summarized way. The development of the physical education teacher's ability to notice the interlinks and to be able to accomplish them is waht is now necessary. Along with this and having in mind his sound learning situation he must achieve a reasonable curtailment of information. In the education of a teacher and in the organization for excellency it must be seen therefore that the teacher may develop the ability to accomplish this curtailment and at the same time have knowledge of the facts besides a reasonable literary view. This can only be shown in actual class examples. In this curtailment work one must not come to definite and outright conclusions but rather see that there is an opening for complementary measures, when learning procedures do not follow what has been planned.

So, teachers forming procedures in which enough room for class practice is not provided can not be satisfactory. Any literary indication mentioned in this article was done mostly by chance. The idea was to show that there is a variety of pedagogy oriented literature with methodological implications.

\section{CAN UNFINISHED FORMS BE USEFUL TO ACTIVE TEACHERS?}

The above mentioned question arises from the previous reflexions. As it does not seem possible to offer teachers learning procedures to be applied literally. suggestions should always offer an opening for specific conditions in a situation.

Therefore we here speak of unfinished forms. Indications given have a generalized feature and need complementation in accordance with each sound iearning process followed by the teacher. The following recommendations have a subjective character once they are based upon the author's knowledge and experience.

- the teacher must always have in mind that he is an assistant to the student. He must help so that the student can learn. At the same time, he must never give up believing that the student has a learning capacity; this demands of him a great deal of flexibility. Whenever the teacher notices that it is impossible for a student to achieve a given goal he must try and change the expectancy of the goal; so whatever the supposed goal may be it is up to the teacher, in many a case in accordance with the student, to command the situation. The teacher is therefore an assistant to the pupil, but learning is up to each person. Learning is not carried out by the teacher.

- extremely significant is the art of knowing how to grade correctly. This is not true just for the physical and energetical area. The social and psychic load can also be too high, too low or adequate. So the teacher must be wise enough to both notice each student's degree of fear and identify difficulties in social contact. Special attention must be given to the grade of information conveyed to the student. He must be given as much information as he can cope with. This is even more significant when it comes to correcting the student.

- as for language expression it is important that the teacher be aware that the student really understands what he has said. For instance, in a ski class guidance is given to accomplish the skill as of the knees. At the same time he can explain how the other parts of the body are employed. This same instruction was given in different ways by different teachers to the same student. This is not negative if the student understands and knows how to distinguish the instructions.

- The twofold aspect of "exploring" the student described by Klafki is of great methodological significance. On the one hand the teacher must see that the student is offered conflicting learning situations to be explored and at the same time to help the student be ready to face these conflicting situations.

- all mentioned aspects are related to the demand for differentiation specially concerning the student's inner differentiation. The teacher is put before a difficult task; he must respect the power of performance and predisposition, tendency of each student; he must consider the different personality characteristics - for instance, more or less fear - and the most satisfactory way in which to use the information. Differentiation possibilities occur mostly when the teacher puts forward a task in which situations demanding decisions from students arise and at the 
same time the students become active individually.

- this is when the teacher is able to give adequate and individualized help. Of course differentiation is also possible through group allotment.

- as for differentiation there is another recommendation: students must always be given the opportunity to perform in a constant and repetitive way in a learning process. Maria Montessori brought forward guidance regarding children's special abilities. Through this way of teaching children reach the ability to grow strong, heading for intrinsic motivation.

- in this situation the trial-and-error form can also be applied but only when students are able to evaluate their results, therefore when they are able to distinguish the right/wrong of their experiences.

- in the same manner it is also advisable that opportunities for global learning are given as much as possible. For instance, a series of exercises with little help has much more of a global feature than when there is a division, classification in functional unities.

- improvement in skill is always troublesome, for it is never totally perfect as compared to the development of skill; this is particularly true for the finest skilfor instance, for athletes who master the task, the teacher may suppose that the athlete's kinesthetic perception is better than the coach's observation ability. Dialogues turn out to be a better help to students when they are based more upon questions to the students than upon instructions from the teacher. For instance, the teacher asks the student: "Did you make a mistake? What was it? What must you be aware of in your next attempt?"

- there must always be an opening for methodological decisions as for students personal characteristics.

- fear of increasing skill mistakes is many times exaggerated. Many mistakes are overcome with time. This however does not mean that there is not the danger of an increase in mistakes.

- as a teacher one must not think that learning processes take place in detail as previously planned. The teacher must always be prepared for unexpected influences or suggestions. Many times they can represent both help in the learning process and negative obstacles.

- teachers are expected to consider complex relations and interlinks and to be able to offer help as regards these identified interlinks. Explaining different features of a skill is much more of an exception in the learning process. This is also true for class planning as for example, it is not satisfactory in elementary school trying to work out the skill of raising the arm separately when throwing: this example is also drawn from physical education class observation.

- all teachers should know that students are learning subjects who have their own way of being.

- therefore it is required from the teacher acceptance and empathy towards students; he must take the student as he is and he can consider measures as for how his behaviour can be modified. The teacher must know how to share with the student, he must understand the student's feeling of fear, for example.

- when the students recognize the teacher as being responsible and pleasant towards them, a good environment for learning is created, which influences positively the joint accomplishment between the teacher and the student.

- most of the suggestions given here are individual oriented. Many of them are a guidance to relations with social behaviour and can be transferred to social learning processes. The idea that one must make a decision between learning readiness support on the one side and social learning on the other side does not meet most of the learning opportunities if we take into account the recommendations here given. In most cases its result is likely to be that learning opportunities in which complex goal ideas follow learning processes are created.

\section{FINAL OBSERVATIONS}

Following retrospective of both the development and the methodological literature situation over the past 25 years, which in the context of this article can only be summarized and with chosen examples, recommendations for physical education teachers were given for the choice of methodological decisions. The author 
argues that "unfinished forms" can be helpful in the search for convenient methodological decisions if the physical education teacher following the suggestions given has the ability to develop helpful complementary decisions of the learning processes planned and followed by him. The "unfinished forms" will then be understood as learning forms, in which the "unknown, the incognito" can still be found.

The references are found in the article in Portuguese.

* Prof. Dr. Phil., Head of the Institut fur

Didaktik des Schulsports da Deutsche Sporthochschule Koln - R.F.A. 